\title{
Reducing adhesive wear in dry deep drawing of high-alloy steels by using MMC tool
}

\author{
Hannes Freiße*, Adrian Ditsche, and Thomas Seefeld \\ BIAS - Bremer Institut für angewandte Strahltechnik GmbH, 28359 Bremen, Germany
}

Received: 14 December 2018 / Accepted: 25 March 2019

\begin{abstract}
Sheet metal forming normally requires the application of lubricants to protect the tool and the sheet against wear. In the case of nonlubricated sheet metal forming, cleaning processes would not be necessary anymore and the process chain could be optimized regarding ecological and economical aspects. However, forming without lubrication leads to an intensive contact between the tool and the sheet. Thus, higher wear occurs and process reliability cannot be ensured for industrial mass production. For dry metal forming of highalloy steels, a new tool concept must be developed to withstand the higher loads. In this work, a laser-generated tool surface with a supporting plateau of hard particles is presented. Spherical fused tungsten carbides were injected into the surface by laser melt injection. The metallic matrix of the composite was rejected by applying laser ablation. In consequence, the hard particles stood out of the matrix and were in direct contact with the sheet material. Dry and lubricated forming experiments were carried out by strip drawing with bending and deep drawing of cups. Within this work, the feasibility of dry metal forming of high-alloy steel could be demonstrated by applying the MMC surface whereby adhesive wear could be reduced.
\end{abstract}

Keywords: Deep drawing / laser beam machining (LBM) / metal matrix composite

\section{Introduction}

The high-alloy steel (1.4301, X5CrNi18-10) is applied in industrial mass production, e.g., in automotive industry or home appliance manufacturing because of the corrosion resistance and high fracture strain. This steel has metastable austenitic structure at room temperature. During forming, the austenite can transform into martensite (transformationinduced plasticity (TRIP) effect). An approach of calculating the martensite content depending on the strain is given in Ref. [1]. Because of the martensitic strain hardening, flow stress increase and higher forming forces are required [2]. The formation of martensite depends, among other, on the temperature [3]. In industrial forming processes, the temperature may rise to $100{ }^{\circ} \mathrm{C}$ within the first 100 strokes [4]. Calculated heat transfer coefficient (HTC) of aluminum bronze and cold working tool steel against high-alloy steel depending on the surface pressure are given in Ref. [5]. Aluminum bronze is a proofed tool material to form high-alloy steel in lubricated deep drawing because of the high HTC [6].

However, to realize dry metal forming, new tool concepts must be developed to withstand the higher loads [7]. In scientific investigations, the surface condition before forming is rarely described, e.g., how the tools and sheets

\footnotetext{
* e-mail: freisse@bias.de
}

were cleaned; which amount of residual contaminations were present on the surface [8].

Dry sliding of high-alloy steel against tool steel 1.2379 resulted in high friction coefficients and adhesive wear [9]. In contrast, good results in dry deep drawing were achieved by applying ceramic tools [10]. Ceramics are expensive and add complexity to setup. Furthermore, ceramics are brittle and, particularly, susceptible to cracking. Another approach to achieve a higher wear resistance is to reinforce the metallic surface with hard particles (metal matrix composite (MMC)) [11]. MMC combines the hardness and wear resistance of the particles with the ductility of the metal and can be generated, e.g., by laser melt injection [12]. Investigations in strip drawing tests with bending revealed that MMC tool surfaces are suitable for lubricated sheet metal forming [13]. Literature presents only a few investigations on lubricated as well as dry sheet metal forming by using MMC tool surfaces.

\section{Experimental details}

\subsection{General}

Forming experiments were carried out by strip drawing with bending and deep drawing of cups. The description of the forming apparatus is given in Ref. [14]. 
Table 1. Mechanical properties of the sheet.

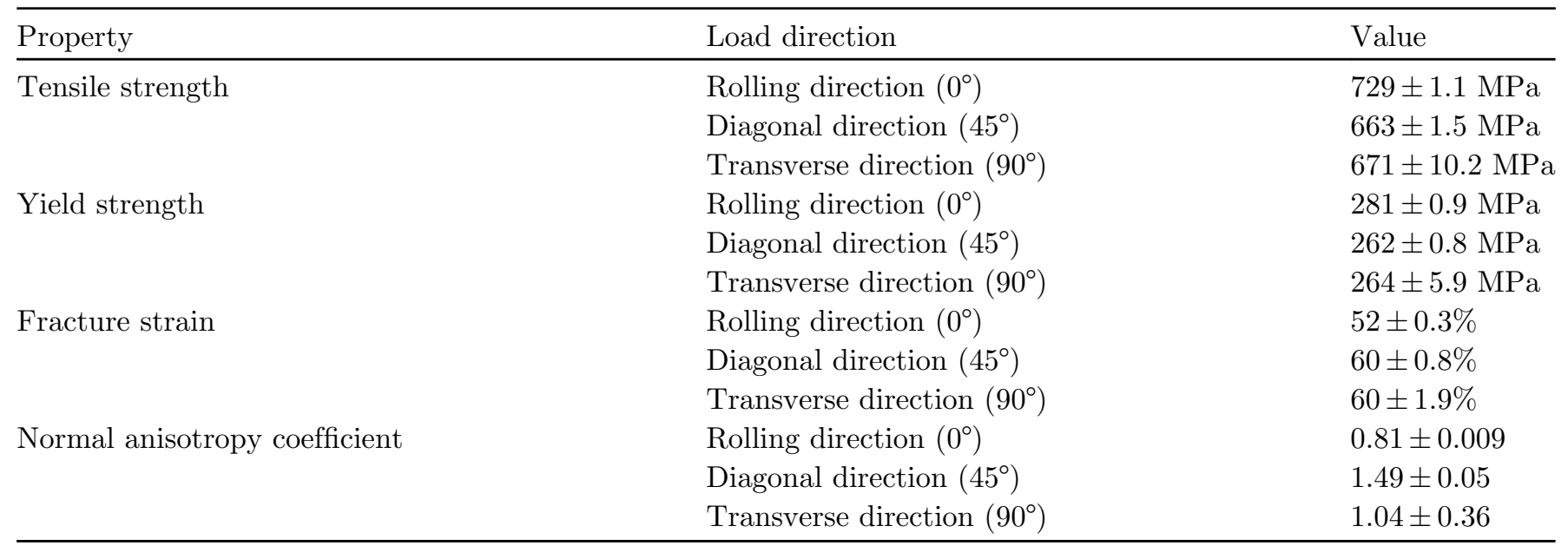
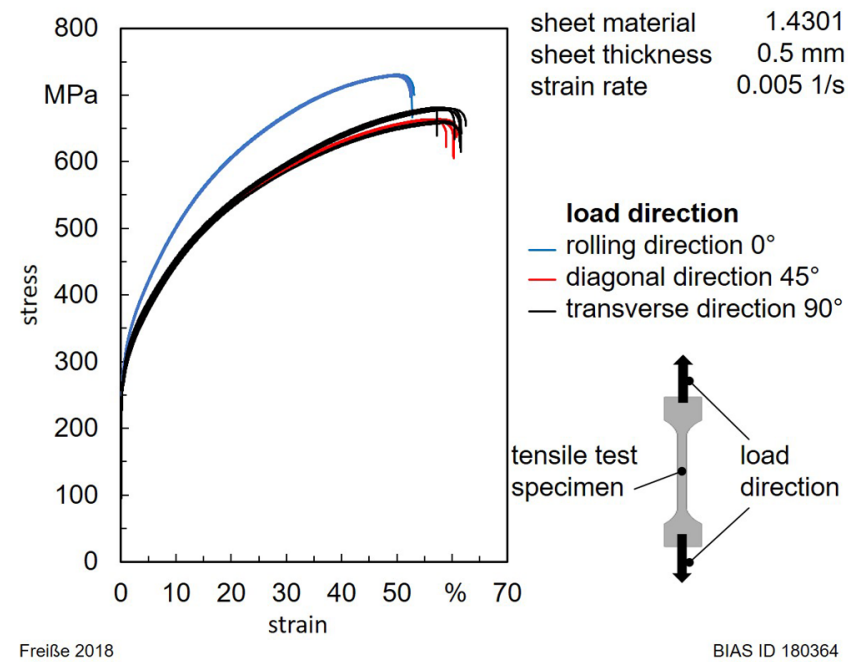

Fig. 1. Stress-strain diagram of the sheet metal.

In this work, three tool materials were applied. The MMC tool surface was made of aluminum bronze $\left(\mathrm{CuAl}_{10} \mathrm{Ni}_{5} \mathrm{Fe}_{4}\right)$ reinforced with spherical fused tungsten carbides (SFTC) with a particle content of MMC of about $50 \%$. Experimental details of reinforcing the surface with hard particles by laser melt injection and of producing a supporting plateau out of hard particles by ablation of the matrix using ultrashort pulse laser are described in Ref. [15].

Two reference tool materials were tested: aluminum bronze $\left(\mathrm{CuAl}_{10} \mathrm{Ni}_{5} \mathrm{Fe}_{4}\right)$ and cold working tool steel (1.2379). The workpiece sheet material was cold-rolled stainless steel 1.4301 with a sheet thickness of $0.5 \mathrm{~mm}$. The sheet surface was not textured and the roughness Sa was $0.35 \pm 0.01 \mu \mathrm{m}$. The hardness was $173 \pm 4$ HV0.5. Mechanical properties were determined in tensile tests according to DIN EN 10002-1 (Tab. 1; Fig. 1). The average of the normal anisotropy coefficient $R$ was calculated by equation (1) and the planar anisotropy factor $R_{\mathrm{p}}$ was calculated by equation (2).
The average of the normal anisotropy coefficient was 1.21 and the planar anisotropy coefficient was -0.57 .

$$
\begin{aligned}
& R=\frac{1}{4} \cdot\left(R_{0}+2 \cdot R_{45}+R_{90}\right) . \\
& R_{p}=\frac{1}{2} \cdot\left(R_{0}-2 \cdot R_{45}+R_{90}\right)
\end{aligned}
$$

To investigate the behavior for dry metal forming, the sheets and the tools were cleaned in an ultrasonic bath with 10\% solution of Tickopur R33 cleaning agent for $10 \mathrm{~min}$. Afterward, the parts were rinsed with deionized water, submerged in pure ethanol for $5 \mathrm{~s}$ and dried with a fan.

At first all dry forming experiments and thereafter all lubricated experiments were carried out with the same tool. The tools were not removed and mounted again between the dry and lubricated experiments to avoid assemblyrelated influences. In each case, three parts were formed. The maximum forming forces were measured, and the average and the standard deviation were investigated.

The surface roughness Sa was measured according to EN ISO 25178 with a measurement area of $200 \times 200 \mu \mathrm{m}^{2}$ using 3D laser scanning confocal microscope Keyence VK-9700 with a magnification of $50 \times$. The low-pass filter (S-filter) was adjusted to $0.5 \mu \mathrm{m}$ (lowest value) and the high-pass filter (L-filter) was set to $0.2 \mathrm{~mm}$ (edge length of the measurement field).

\subsection{Laser melt injection}

Laser melt injection (LMI) of multitracks was realized by variation of the powder mass flow, overlapping degree and laser power. On these tracks, the powder catchment efficiency and the hard particle content were analyzed.

The overlapping degree of the laser melt-injected tracks $\mathrm{OD}_{\mathrm{T}}$ were determined in consideration of the track width $w$ [16] and the track offset $\Delta y$ by equation (3):

$$
O D_{T}=(w-\Delta y) / w * 100 \%
$$




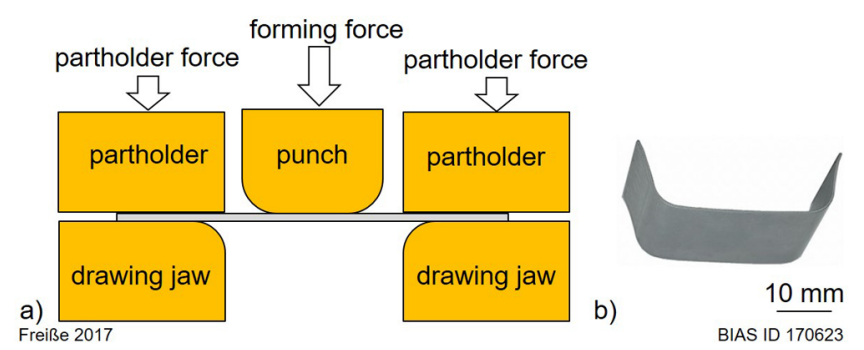

Fig. 2. (a) Sketch of strip drawing with bending. (b) Bended strip as a U-shaped component.

To calculate the powder catchment efficiency $\eta$ of the LMI process, equation (4) was used with the mass increase $\Delta m_{\mathrm{p}}$ of the specimen, the travel speed $v$, the powder feed rate $\dot{m}_{\mathrm{p}}$, and the total length of the laser melt-injected track $l$.

$$
\eta=\frac{\Delta m * v}{\dot{m}_{p} * l}
$$

The particle contents of the LMI tracks were determined by the software MATLAB Image Processing Toolbox [16]. The region of interest where the particle content should be measured was defined by an intersection of two circles forming a lens-shaped region. Grayscale images were evaluated with "global image threshold using Otsu's method" [17] of the MATLAB software to distinguish the particles and matrix of the MMC.

\subsection{Strip drawing with bending}

A sketch of strip drawing with bending is depicted in Figure 2. The tools were machined by wire cut electrical discharge machining (EDM). The punch diameter was $\varnothing$ $30 \mathrm{~mm}$, and the punch radius was $4 \mathrm{~mm}$. The sheets were of $52 \times 20 \mathrm{~mm}^{2}$ and were cut in rolling direction $\left(0^{\circ}\right)$.

A strip drawing die with MMC surface is shown in Figure 3. After EDM machining, the surface roughness Sa amounted to $0.75 \pm 0.04 \mu \mathrm{m}$. Pores were visible in the MMC surface, which resulted from the process of laser melt injection. At first, forming experiments were performed without depression. Afterward, the surfaces were laser ablated and a depression of $5 \mu \mathrm{m}$ was set.

Forming experiments were carried out by variation of the drawing radius (from 5 to $7 \mathrm{~mm}$ ) and two different initial blankholder pressures were applied (1.6 and 3.2 MPa).

The tools of aluminum bronze and cold working tool steel were hardened. The roughness $\mathrm{Sa}$ of the bronze surface amounted to $0.36 \pm 0.05 \mu \mathrm{m}$ and that of the steel surface $0.45 \pm 0.03 \mu \mathrm{m}$. Forming experiments were carried out by variation of the drawing radius $(3-7 \mathrm{~mm})$, by variation of the drawing clearance $(0.7-1.5 \mathrm{~mm})$ and two different initial blankholder pressure were applied (1.6 and $3.2 \mathrm{MPa}$ ).

\subsection{Deep drawing of cups}

Details of the experimental setup are given in Ref. [14]. The die radius was $4 \mathrm{~mm}$. The initial blankholder pressure was

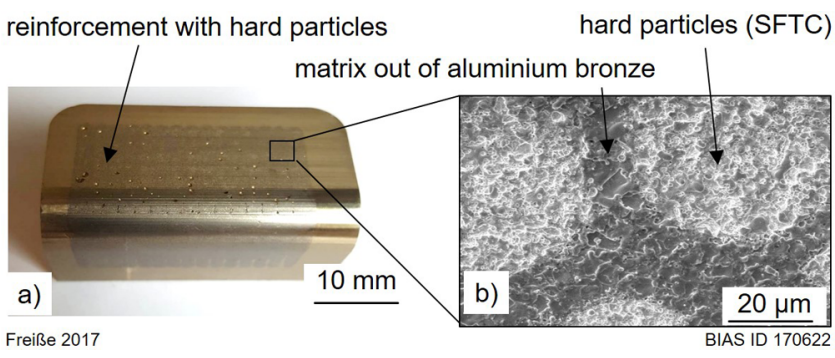

Fig. 3. (a) Drawing die reinforced with hard particles machined by wire EDM. (b) Scanning electron microscope (SEM) image of the surface.

Table 2. Material, manufacturing process, and drawing clearance of the drawing dies.

\begin{tabular}{llll}
\hline Tool no. & Material & Machined & $\begin{array}{l}\text { Drawing } \\
\text { clearance }\end{array}$ \\
\hline 1 & Bronze & Milled & $0.7 \mathrm{~mm}$ \\
2 & & & $1 \mathrm{~mm}$ \\
3 & & & \\
4 & & & $0.7 \mathrm{~mm}$ \\
5 & Steel & Die-sinking EDM & $1 \mathrm{~mm}$ \\
6 & Bronze & & \\
7 & MMC & & \\
8 & & & \\
\hline
\end{tabular}

3.2 MPa. Drawing dies were tested with a MMC surface, aluminum bronze, and cold working steel (Tab. 2). Eight tools were applied: three tools with a drawing clearance of $0.7 \mathrm{~mm}$ and five tools with a drawing clearance of $1 \mathrm{~mm}$. The tools were machined by milling and die-sinking EDM.

Dry and lubricated forming was performed (three sheets each) and afterward the tools were removed, cleaned, and the set of experiments (dry and lubricated) was repeated one more time. The maximum drawing ratio in dry metal forming was investigated by varying the blank diameter and using bronze tool 3 .

The milled drawing dies out of steel had a surface roughness Sa of $0.3 \pm 0.03 \mu \mathrm{m}$ and the milled drawing dies out of bronze had a surface roughness $\mathrm{Sa}$ of $0.6 \pm 0.02 \mu \mathrm{m}$.

The microgeometry of the MMC surface produced by die-sinking EDM differed significantly from the wire-cut EDM-machined surface of the tools for strip drawing with bending. No plane surface was produced by die-sinking EDM (see Fig. 4). The aluminum bronze matrix was removed stronger. The depression varied between 20 and $100 \mu \mathrm{m}$. The wire cutting resulted in uneven removal of the surface, where removal of the matrix material was more pronounced than of the hard particles (see Fig. 4). The height difference was 20-100 $\mu \mathrm{m}$.

\subsection{Calculated true blankholder pressure}

The initial blankholder force was $3.2 \mathrm{MPa}$ for this particular calculation. The blankholder force was kept 

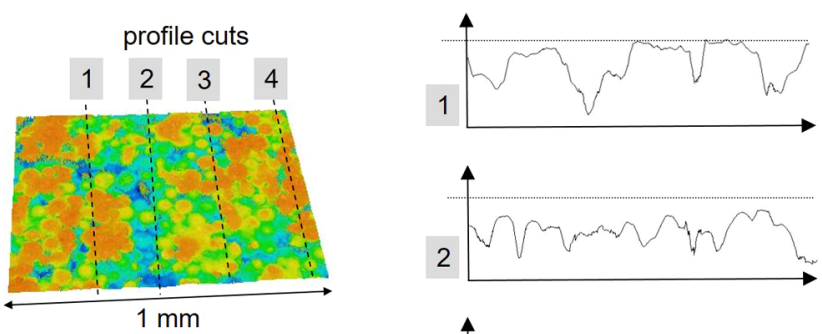

2

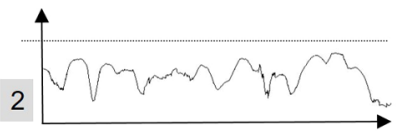

120

3

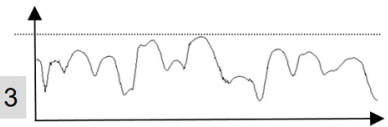

$\mu \mathrm{m}$

40

0

Freiße 2017

Fig. 4. Three-dimensional laser-scanning confocal microscope image and profile cuts of the MMC surface machined by diesinking EDM.

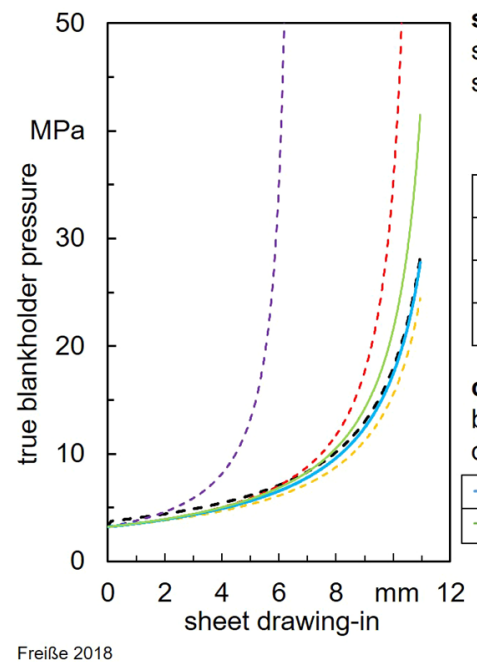

strip drawing with bending sheet length sheet width

\begin{tabular}{|c|c|c|}
\cline { 2 - 3 } \multicolumn{1}{c|}{} & $\begin{array}{c}\text { die } \\
\text { radius }\end{array}$ & $\begin{array}{c}\text { drawing } \\
\text { clearance }\end{array}$ \\
\hline--- & $4 \mathrm{~mm}$ & $0.7 \mathrm{~mm}$ \\
\hline--- & $4 \mathrm{~mm}$ & $1.5 \mathrm{~mm}$ \\
\hline-- & $3 \mathrm{~mm}$ & $0.7 \mathrm{~mm}$ \\
\hline--- & $7 \mathrm{~mm}$ & $0.7 \mathrm{~mm}$ \\
\hline
\end{tabular}

deep drawing of cups

blank diameter

die radius

- drawing clearance $0.7 \mathrm{~mm}$ - drawing clearance $1 \mathrm{~mm}$

BIAS ID 180062

Fig. 5. Example on calculated blankholder pressures up to a sheet draw-in of $11 \mathrm{~mm}$.

constant and the parts were completely drawn in. So, the area under the blankholder decreased and the true blankholder pressure tended toward infinity. Exemplarily calculated blankholder pressures up to a sheet draw-in of $11 \mathrm{~mm}$ are depicted in Figure 5. The larger the drawing radius and the wider the drawing clearance, the earlier was the increase of the true blankholder pressure.

Furthermore, the amount of sheet under the blankholder depends on the die geometry. The smallest sheet drawing-in of $6.6 \mathrm{~mm}$ occurred in strip drawing when bending with a die radius of $7 \mathrm{~mm}$, whereas the largest drawing-in of $12.6 \mathrm{~mm}$ occurred when bending with a die radius of $3 \mathrm{~mm}$.

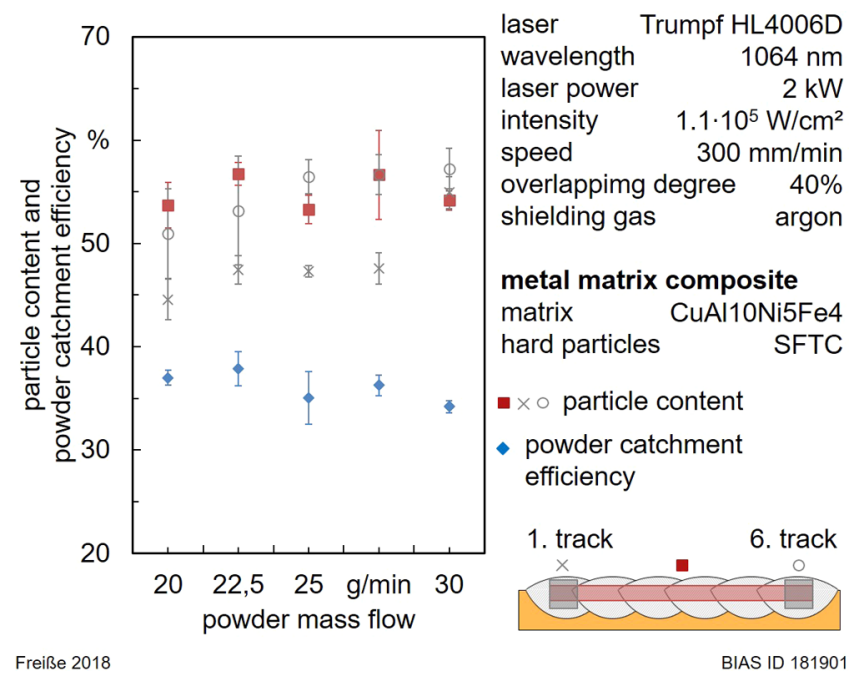

Fig. 6. Variation of powder mass flow in laser melt-injected multitracks showing a constant particle content and a decrease of powder catchment efficiency.
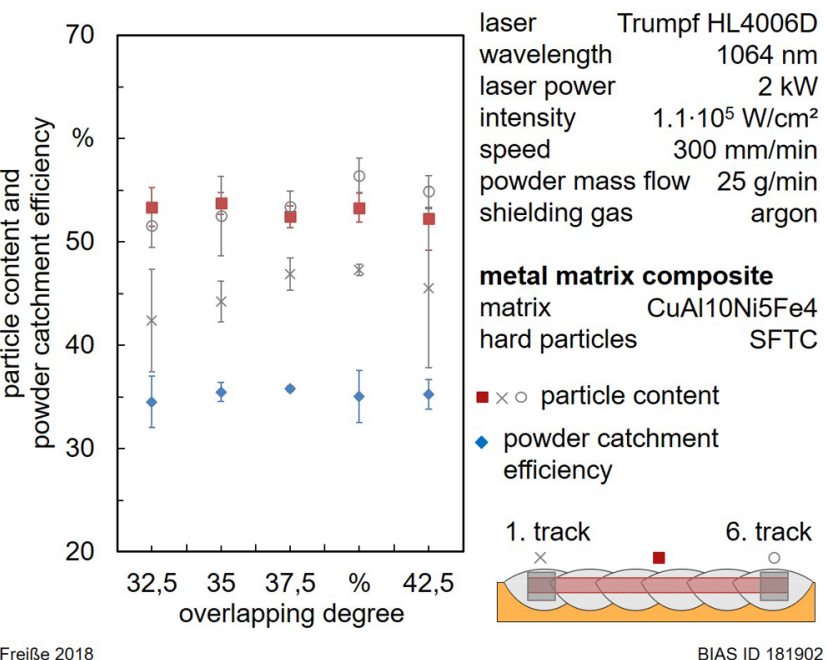

Fig. 7. Variation of overlapping degree in laser melt-injected multitracks showing a constant particle content and powder catchment efficiency.

\section{Results}

\subsection{Analysis}

The powder mass flow had no significant influence on the particle content in LMI multitracks as shown in Figure 6. In the first LMI track, the particle content is about $10 \%$ lower compared to the next tracks. A slight decrease of the powder catchment efficiency from 37.5 to $35 \%$ can be observed.

The particle content of LMI multitracks with different overlapping degrees was constant at $55 \%$, as shown in Figure 7 . Here the first track had also a lower particle content compared to the next tracks. The powder catchment efficiency was constantly about $35 \%$. 

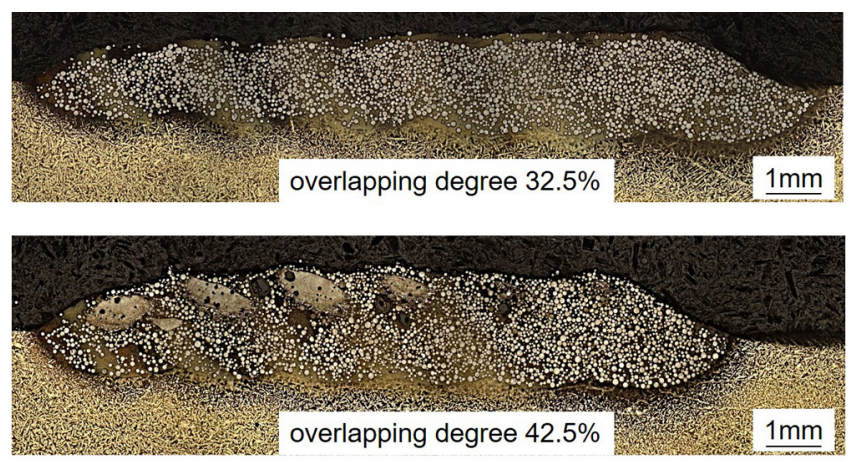

Freiße 2018

BIAS ID 181904

Fig. 8. Metallographic image of laser melt-injected multitracks with a change in track geometry depending on the overlapping degree.

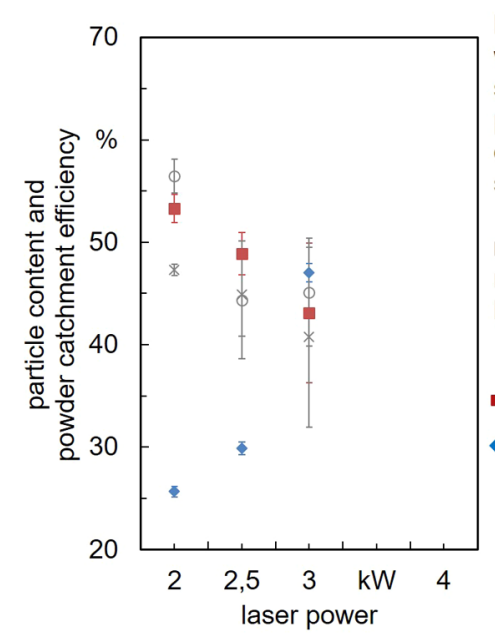

Freiße 2018

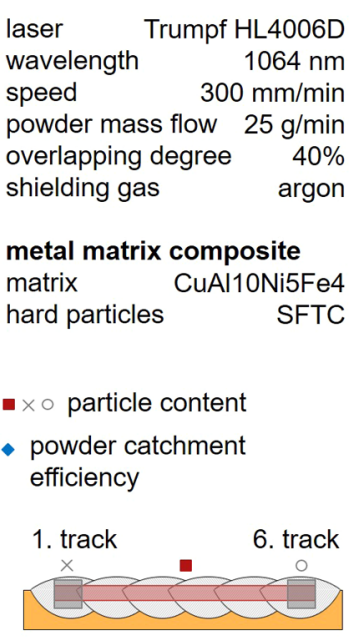

BIAS ID 181903
Fig. 9. Variation of laser power in laser melt-injected multitracks showing a decrease of the particle content and an increase of the powder catchment efficiency.

The geometry of LMI multitracks changes with the overlapping degree, as shown in Figure 8. A smaller overlapping degree of $32.5 \%$ leads to a broad flat LMI multitrack. For an overlapping degree of $42.5 \%$, the multitrack is getting higher and narrowed. On the top of the first tracks, the tungsten carbide was fused locally together to an agglomerate.

Variation of the laser power had a significant influence on the particle content and powder catchment efficiency, as shown in Figure 9. The particle content is decreasing from 55 to $45 \%$ by an increase of the laser power. On the other side, the powder catchment efficiency is increasing from $25 \%$ up to $45 \%$. After reaching the process limit of $3 \mathrm{~kW}$, a regular laser melt injection of multitracks is not possible without any side effects like melting the particles.

A metallographic image of the MMC tool surface is shown in Figure 10. The spherical fused tungsten carbide particles are homogenously distributed in the aluminum bronze and cracks as well as pores cannot be detected.

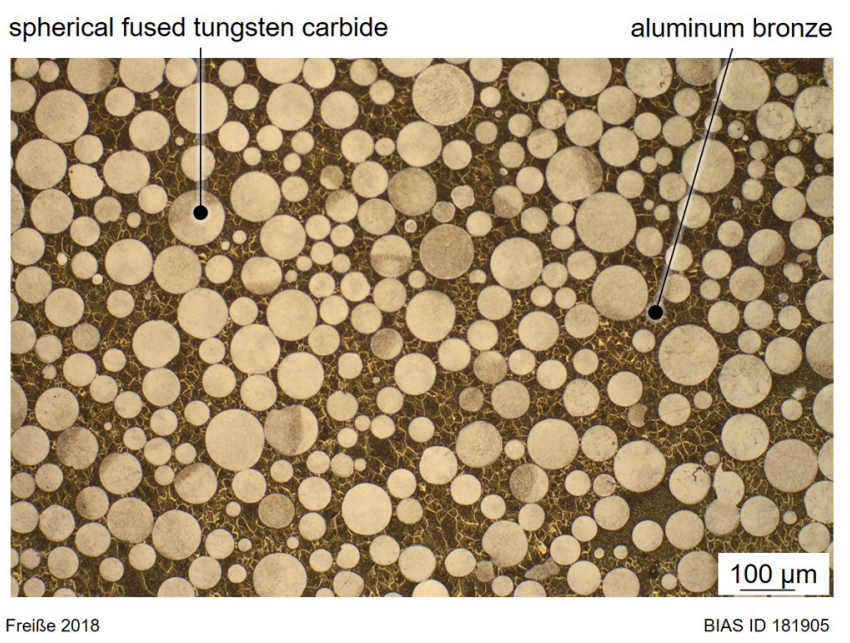

Fig. 10. Homogenous distribution of spherical fused tungsten carbide particles in aluminum bronze after laser melt injection.

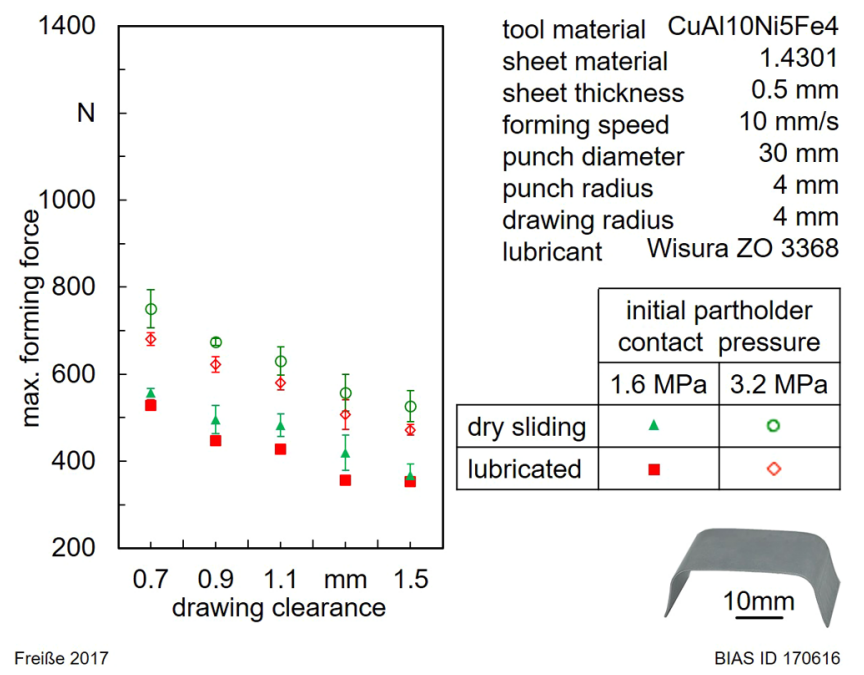

Fig. 11. Maximum forming forces using bronze tool under variation of the drawing clearance.

\subsection{Strip drawing with bending}

\subsubsection{Reference tool materials}

The influence of the drawing clearance on the forming force by using bronze tool is shown in Figure 11 and by using steel tool is shown in Figure 12.

No significant influence of the tool material was investigated even in dry forming. The forming forces fluctuated between 353 and $800 \mathrm{~N}$. Applying either lubrication or smaller drawing clearance or lower blankholder pressure resulted in lower forming forces.

A significance analysis was carried out for each experimental variation: increasing the initial blankholder pressure, forming without lubrication and reducing the drawing clearance.

For calculating the impact factor on the increased forming force by higher initial blankholder pressure and forming without lubrication, at first the ratio between the 
high and low maximum forming force for each drawing clearance was determined. For example, the influence factor for increasing the initial blankholder pressure for a drawing clearance of $0.7 \mathrm{~mm}$ by using steel tool (Fig. 7), the ratio in dry sliding was calculated as $800 \mathrm{~N} / 525 \mathrm{~N}=1.52$ and the ratio for lubricated sliding was calculated as
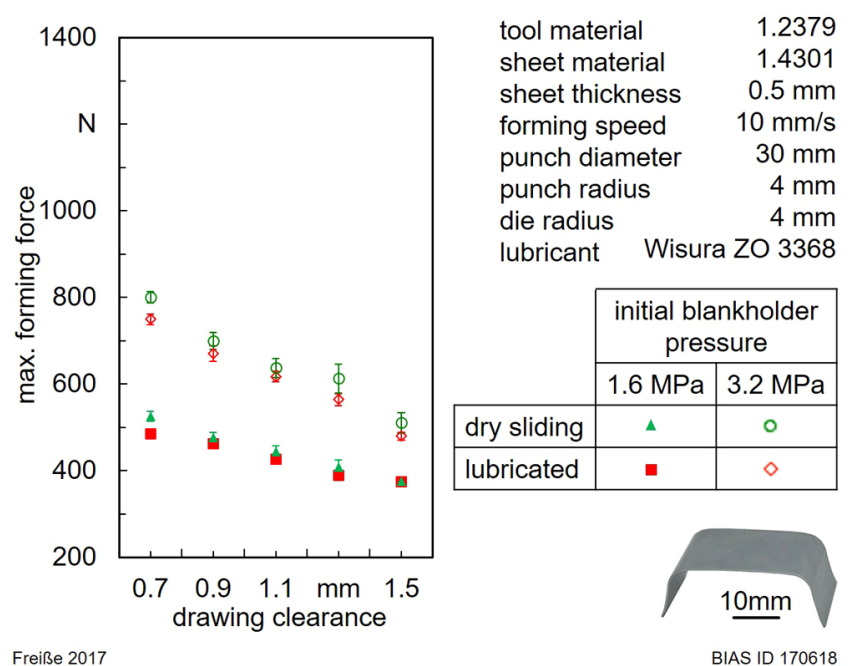

Fig. 12. Maximum forming forces using steel tool under variation of the drawing clearance.

Table 3. Factors for increasing the forming forces in the case of using bronze tool and steel tool.

\begin{tabular}{lll}
\hline Variation & Bronze tool & Steel tool \\
\hline $\begin{array}{l}\text { Increasing the initial } \\
\text { blankholder pressure }\end{array}$ & $1.36 \pm 0.05$ & $1.45 \pm 0.07$ \\
Without lubrication & $1.10 \pm 0.04$ & $1.05 \pm 0.02$ \\
\hline
\end{tabular}

$749 \mathrm{~N} / 485 \mathrm{~N}=1.54 \mathrm{~N}$. Thereafter, the averages and standard deviations of these ratios for all drawing clearances were calculated $(1.45 \pm 0.07)$.

For example, the influence factor for forming without lubrication for a drawing clearance of $0.7 \mathrm{~mm}$ by using steel tool (Fig. 7), the ratio for forming by using a low initial blankholder pressure was calculated as $525 \mathrm{~N} / 485 \mathrm{~N}=1.08$ and the ratio for forming by using a high initial blankholder pressure was calculated as $800 \mathrm{~N} / 749 \mathrm{~N}=1.07$. Thereafter, the averages and standard deviations of these ratios for all drawing clearances were calculated $(1.05 \pm 0.02)$.

Increasing the initial blankholder pressure had a higher influence compared to forming without lubrication (Tab. 3).

The significance analysis of variation of the drawing clearance was carried out by a linear regression analysis. The results of the linear regression analysis in the case of using bronze tool is given in Table 4 and in the case of using steel tool is given in Table 5. The influence of the drawing clearance was higher in the case of higher initial blankholder pressure. The slopes of the regression were slightly higher in the case of forming without lubrication.

The maximum forming forces under variation of the drawing radius using bronze tool are shown in Figure 13 and for the steel tool in Figure 14.

The forces were slightly higher in the case of using steel tool with smaller drawing radius compared to bronze tool. Forming forces from 247 to $1058 \mathrm{~N}$ were measured. The forces were lower in the case of lubricated forming compared to dry metal forming. By applying higher blankholder pressure, the forming forces were increased. Forming with smaller drawing radius resulted in higher forming force.

The main influence factor increasing the forming force was increasing the initial blankholder pressure (Tab. 6). The lowest impact on the forming forces was determined by dry forming.

The linear regression analysis of variation of the drawing radius in the case of using bronze tool is given in Table 7 and in the case of using steel tool is given in

Table 4. Regression analysis of variation of the drawing clearance in the case of using bronze tool.

\begin{tabular}{llll}
\hline Lubrication & Initial blankholder pressure & Slope of the regression & Determination coefficient $R^{2}$ \\
\hline With & $1.6 \mathrm{MPa}$ & $y=-44.2 x+554.9$ & 0.923 \\
Without & & $y=-45.7 x+601.3$ & 0.973 \\
With & $3.2 \mathrm{MPa}$ & $y=-53.2 x+731.9$ & 0.991 \\
Without & & $y=-56.4 x+796.8$ & 0.984 \\
\hline
\end{tabular}

Table 5. Regression analysis of variation of the drawing clearance in the case of using steel tool.

\begin{tabular}{llll}
\hline Lubrication & Initial blankholder pressure & Slope of the regression & Determination coefficient $R^{2}$ \\
\hline With & $1.6 \mathrm{MPa}$ & $y=-26.6 x+515.7$ & 0.986 \\
Without & & $y=-36.7 x+555.9$ & 0.993 \\
With & $3.2 \mathrm{MPa}$ & $y=-64.6 x+809.5$ & 0.992 \\
Without & & $y=-66.6 x+851.47$ & 0.964 \\
\hline
\end{tabular}


Table 8. The influence of the drawing radius was higher in the case of higher initial blankholder pressure. It is remarkable that the slope of the regression was lower by forming without lubrication in the case of lower initial
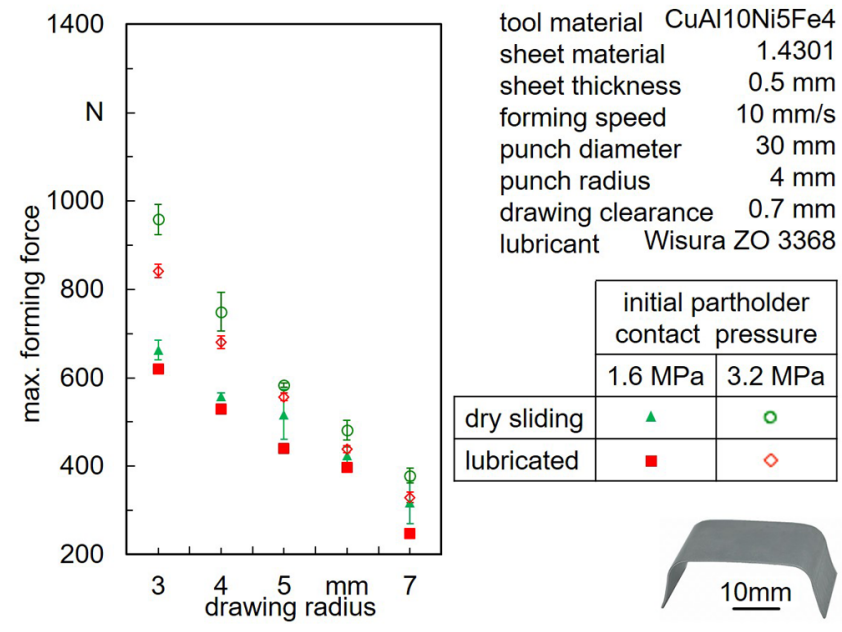

Freiße 2017

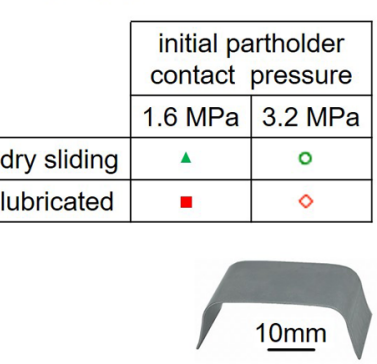

BIAS ID 170615

Fig. 13. Maximum forming forces using bronze tool under variation of the drawing radius.
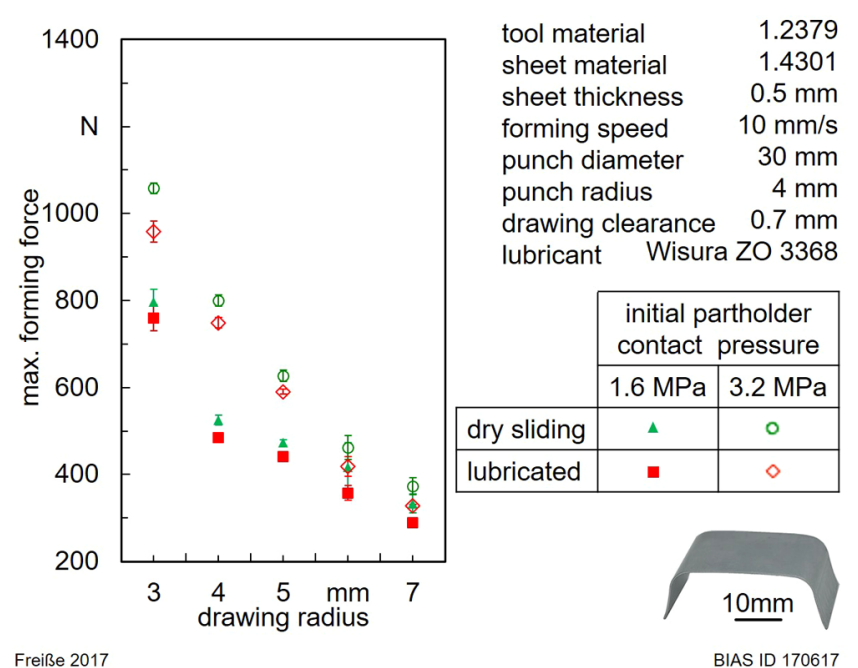

Fig. 14. Maximum forming forces using steel tool under variation of the drawing radius. blankholder pressure for both the tool materials. Furthermore, the influence of the drawing radius was higher when steel was used as tool material.

\subsubsection{MMC tool}

In Figure 15, the forming forces are shown in the case of using MMC tool without depression. Forming forces from 365 to $1130 \mathrm{~N}$ were measured. The results of the forming tests by applying the MMC tool surface with a depression of $5 \mu \mathrm{m}$ are depicted in Figure 16.

The values of the forming forces varied between 536 and $1197 \mathrm{~N}$. The forces increased when using smaller drawing radius, higher blankholder pressure, and no lubrication. These effects can be observed by applying the MMC tool surface without as well as with a supporting plateau of hard particles.

Factors for increasing the forming forces by variation in the case of using MMC tool surface with and without lubrication are given in Table 9. The lowest impact on the forming force resulted by applying higher blankholder pressure. The influence of forming without lubrication had higher influence on the forming force compared to the increased initial blankholder pressure. Particularly, using a MMC surface with depression led to lower impact of the increased initial blankholder pressure and avoidance of lubrication on the forming force.

The results of the linear regression analysis of variation of the drawing radius in the case of using MMC tool without depression is given in Table 10 and in the case of using MMC tool with depression is given in Table 11.

The slope of the regression was increased either by applying higher initial blankholder pressure or by forming without lubrication. It is remarkable that the influence of the drawing radius on the forming force was lower by using MMC with depression in the case of higher initial blankholder pressure.

Table 6. Factors for increasing the forming forces in the case of using bronze tool and steel tool.

\begin{tabular}{lll}
\hline Variation & Bronze tool & Steel tool \\
\hline $\begin{array}{l}\text { Increasing the initial } \\
\text { blankholder pressure }\end{array}$ & $1.25 \pm 0.1$ & $1.28 \pm 0.15$ \\
Without lubrication & $1.19 \pm 0.06$ & $1.10 \pm 0.04$ \\
\hline
\end{tabular}

Table 7. Regression analysis of variation of the drawing radius in the case of using bronze tool.

\begin{tabular}{llll}
\hline Lubrication & Initial blankholder pressure & Slope of the regression & Determination coefficient $R^{2}$ \\
\hline With & $1.6 \mathrm{MPa}$ & $y=-87.9 x+710.2$ & 0.974 \\
Without & & $y=-82.1 x+742.43$ & 0.983 \\
With & $3.2 \mathrm{MPa}$ & $y=-126.7 x+949.4$ & 0.994 \\
Without & & $y=-142.8 x+1058.9$ & 0.973 \\
\hline
\end{tabular}


Table 8. Regression analysis of variation of the drawing radius in the case of using steel tool.

\begin{tabular}{llll}
\hline Lubrication & Initial blankholder pressure & Slope of the regression & Determination coefficient $R^{2}$ \\
\hline With & $1.6 \mathrm{MPa}$ & $y=-107.1 x+787.9$ & 0.878 \\
Without & & $y=-103.6 x+819.9$ & 0.867 \\
With & $3.2 \mathrm{MPa}$ & $y=-159.1 x+1086$ & 0.984 \\
Without & & $y=-170.6 x+1176$ & 0.97 \\
\hline
\end{tabular}
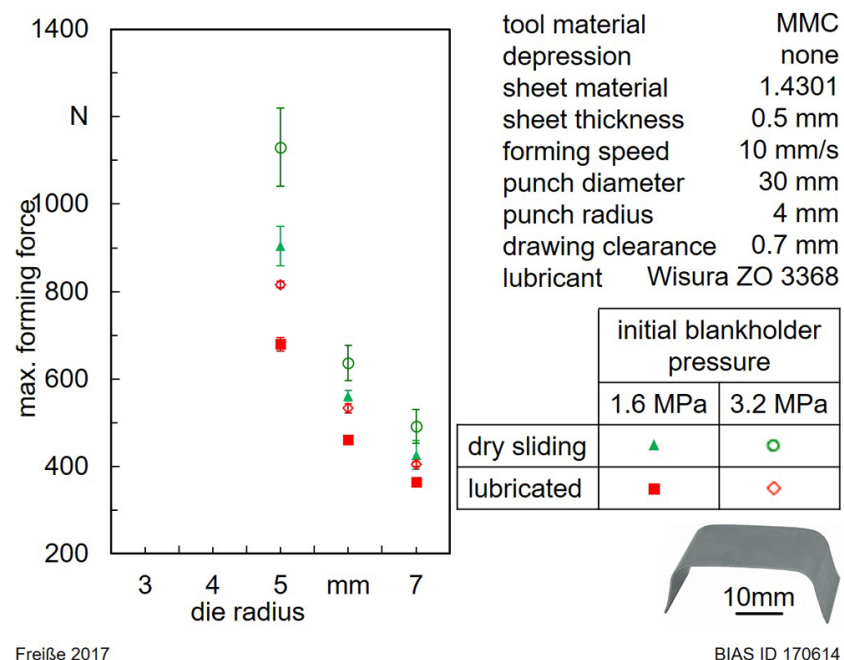

Fig. 15. Maximum forming forces using MMC tool without depression.

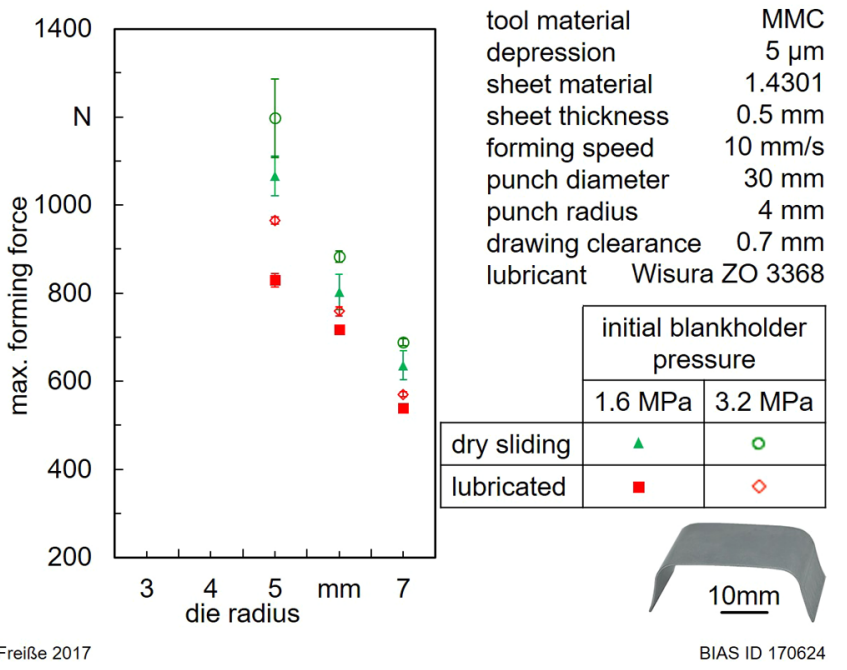

Fig. 16. Maximum forming forces using MMC tool with $5 \mu \mathrm{m}$ depression.

Table 9. Factors for increasing the forming forces in the case of using MMC tool surface.

\begin{tabular}{lll}
\hline Variation & Without depression & $5 \mu \mathrm{m}$ depression \\
\hline Increasing initial blankholder pressure & $1.17 \pm 0.04$ & $1.09 \pm 0.03$ \\
Without lubrication & $1.25 \pm 0.08$ & $1.20 \pm 0.05$ \\
\hline
\end{tabular}

Table 10. Regression analysis of variation of the drawing radius in the case of using MMC tool without depression.

\begin{tabular}{llll}
\hline Lubrication & Initial blankholder pressure & Slope of the regression & Determination coefficient $R^{2}$ \\
\hline With & $1.6 \mathrm{MPa}$ & $y=-157.4 x+1131.2$ & 0.951 \\
Without & & $y=-238.8 x+1585.5$ & 0.941 \\
With & $3.2 \mathrm{MPa}$ & $y=-205.5 x+1406.8$ & 0.955 \\
Without & & $y=-319.4 x+2030.3$ & 0.909 \\
\hline
\end{tabular}

Table 11. Regression analysis of variation of the drawing radius in the case of using MMC tool with depression.

\begin{tabular}{llll}
\hline Lubrication & Initial blankholder pressure & Slope of the regression & Determination coefficient $R^{2}$ \\
\hline With & $1.6 \mathrm{MPa}$ & $y=-145 x+1275.7$ & 0.983 \\
Without & & $y=-215 x+1695.1$ & 0.984 \\
With & $3.2 \mathrm{MPa}$ & $y=-197.2 x+1553.2$ & 0.999 \\
Without & & $y=-254.4 x+1940.5$ & 0.982 \\
\hline
\end{tabular}




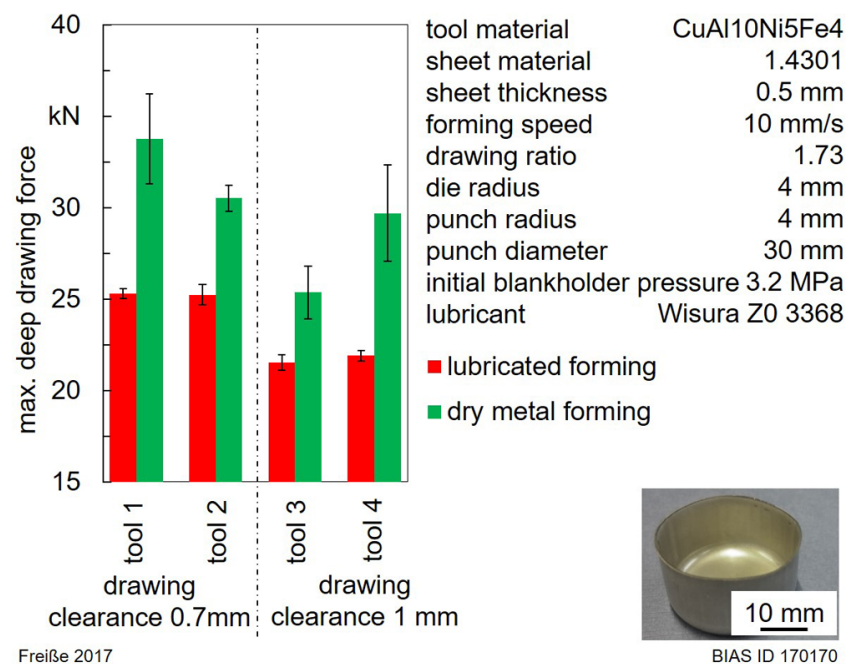

Fig. 17. Maximum deep drawing forces using milled bronze tool under variation of the drawing clearance.

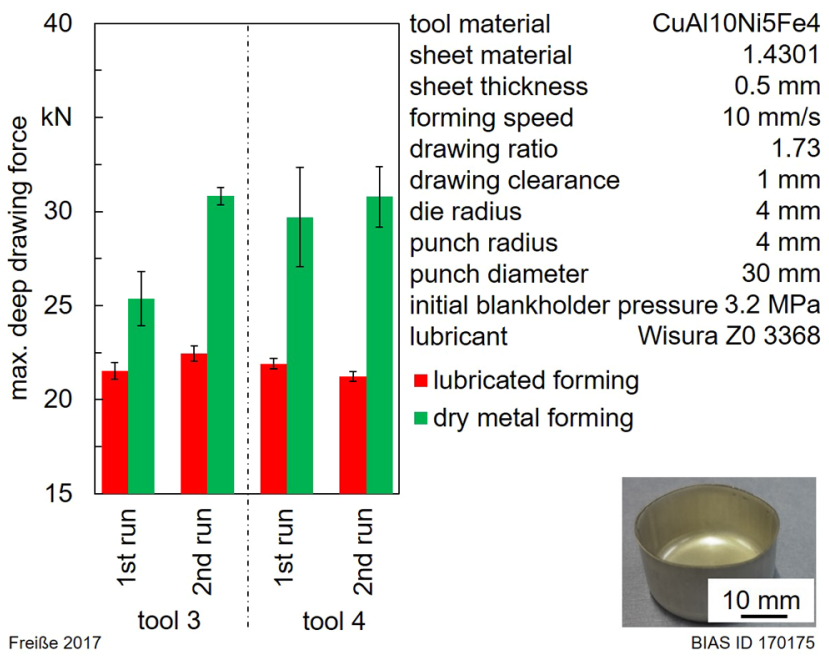

Fig. 18. Maximum deep drawing forces using milled bronze tool by repeated forming tests.

\subsection{Deep drawing of cups}

\subsubsection{Milled tools}

In Figure 17 the deep drawing forces are shown by using two tools in each case with a drawing clearance of 0.7 and $1 \mathrm{~mm}$. The deep drawing forces were lowered about $15 \%$ by applying higher drawing clearance in the case of lubricated deep drawing. A reproducibility of the lubricated forming results could be achieved by applying different tools. In contrast, in dry metal forming, there were high deviations between the results of applying different tools with the same drawing clearance. On average, the forces were lower in the case of applying higher drawing clearance. Significant higher standard deviations of the forming forces were found in the case of dry metal forming.

The experiments were repeated with tools 3 and 4 (Fig. 18). The tools were removed, cleaned, and mounted
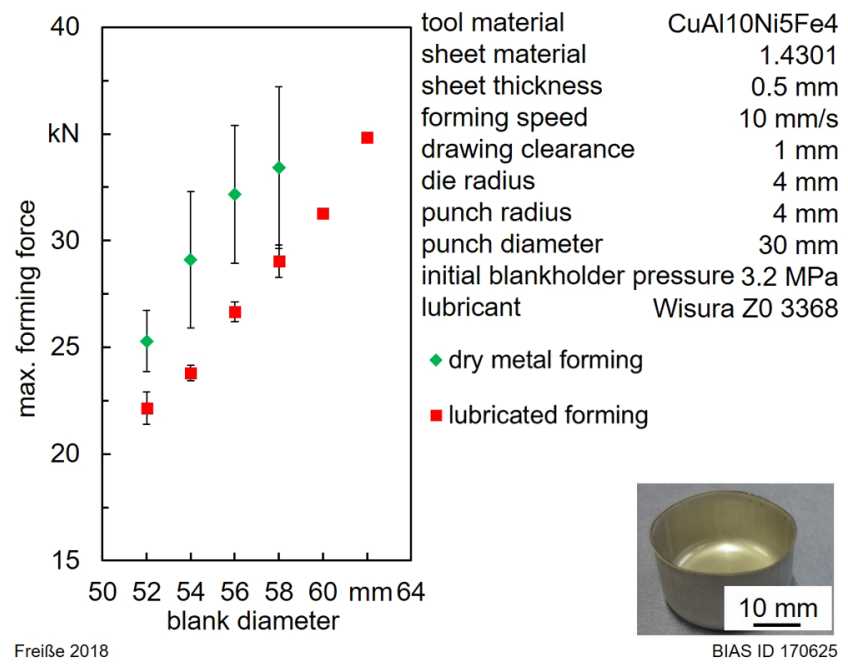

Fig. 19. Maximum deep drawing forces using milled bronze tool under variation of the blank diameter using bronze tool 3 .

again. The deep drawing forces were reproducible in the case of lubricated forming.

The highest difference was about $4 \%$ by using tool 3 . However, the results differ strongly in the case of dry metal forming. The highest difference was about $22 \%$ by using tool 3 .

By forming different blank diameters from 52 to $62 \mathrm{~mm}$ and using bronze tool 3 , the drawing ratio was varied from 1.73 to 2.07 . In dry metal forming, a maximum drawing ratio of 1.93 was investigated (Fig. 19). Using larger blank diameter than $58 \mathrm{~mm}$ in dry metal forming resulted in cup base fractures. By reducing the initial blankholder pressure, the simultaneous occurrence of cup base fracture and wrinkles formation of first order was observed, which was an indication for the process limit in dry metal forming.

Blank diameter of $62 \mathrm{~mm}$ could be formed in lubricated deep drawing. Larger diameters could not be applied because of geometric circumstances of the deep drawing apparatus.

The maximum forming forces in lubricated forming by using steel tool were comparable to those in the case of using bronze tool. Dry metal forming by using steel tool was not possible. Applying a blankholder pressure of $3.2 \mathrm{MPa}$ resulted in cup base fracture. When the blankholder pressure was reduced to $2.8 \mathrm{MPa}$, wrinkle formation of the first order and cup base fracture occurred at the same time (Fig. 20).

\subsubsection{EDM tools}

In Figure 21, the maximum forming forces are shown by using tools machined by die-sinking EDM out of bronze and MMC. The forming forces by using the EDM-machined bronze tool were about $20 \%$ lower compared to the forming forces investigated by using the milled bronze tool. Dry metal forming led to higher forming forces compared to lubricated forming. The forces were higher when applying the MMC tools. Two MMC tools were tested and a reproducible result was achieved. 


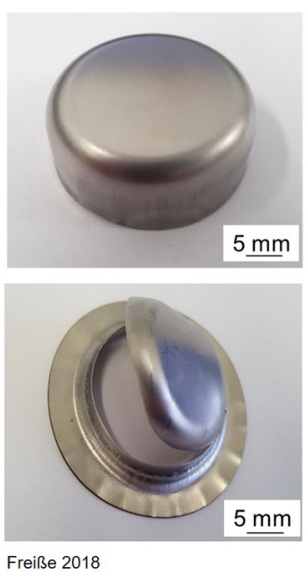

\section{dry metal forming}

blankholder force

initial blankholder pressure

max. deep drawing force

Fig. 20. Deep drawing by using tool out of tool steel and a drawing clearance of $0.7 \mathrm{~mm}$.

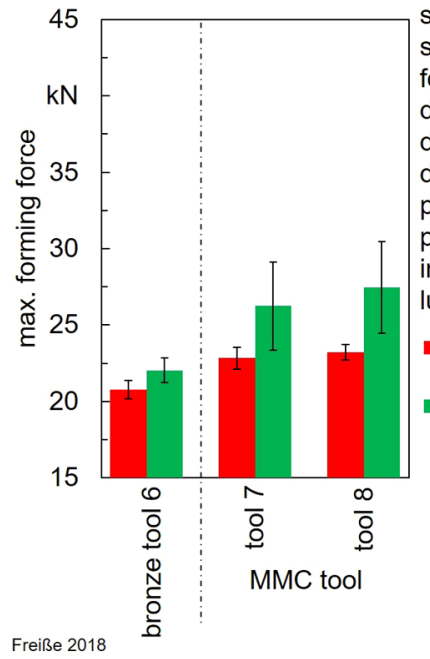

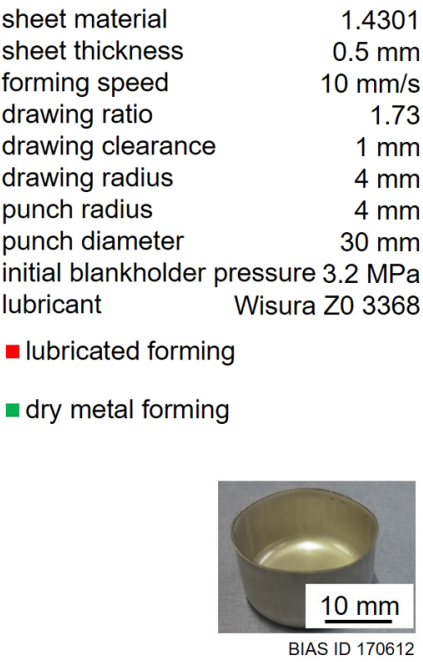

Fig. 21. Maximum forming forces using tools machined by die-sinking EDM.

The formed cups were analyzed by EDX (electron diffraction X-ray) analysis (Fig. 22). Adhesive wear was determined. This can be traced back to the detected copper $(\mathrm{Cu})$ from the tool on the steel sheet $(\mathrm{Fe})$. The adhesive wear could be significantly reduced by applying the MMC tool. However, more scoring occurred when MMC acted as tool material. It is assumed that the particles penetrated the sheet material and caused the scoring. The anisotropic properties of the cold rolled sheet led to earing at the cups. Exemplarily, hardness measurement revealed that the hardness in the sheet was increased up to 360 HV0.5. The cups became magnetic, which can be traced back to the formation of martensite.

\section{Discussion}

Powder mass flow, overlapping degree, and laser power had an influence on the weld pool and track geometry of LMI

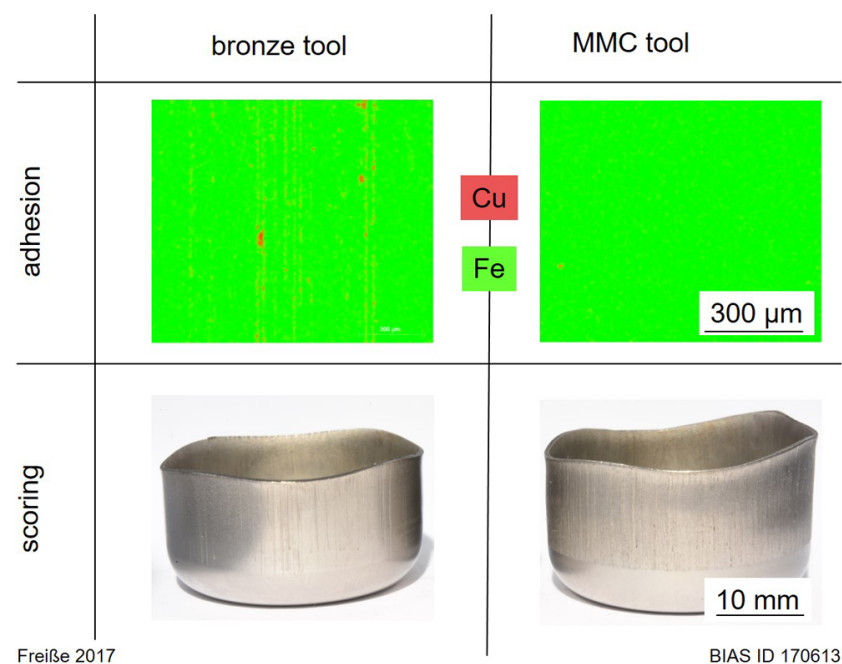

Fig. 22. Adhesive and abrasive wear in the deep drawn cups using bronze tool with and without hard particles.

multitracks. Despite increasing the powder feed rate, the weld pool can trap a limited number of particles. Thus, the particle content is constant, while the powder catchment efficiency decreases. The variation of the overlapping degree changes the track geometry and volume. A process limit was observed at an overlapping degree of $42.5 \%$ because spherical fused tungsten carbide particles melted together to an agglomerate and a regular LMI multitrack cannot be obtained anymore. An increase of the laser power had a better powder catchment efficiency in LMI multitracks due to the larger weld pool, which can absorb more particles.

Sheet forming experiments were carried out by variation of the drawing clearance and drawing radius to investigate the influence on the forming force. Lower drawing clearances [18] and smaller drawing radius [19] lead to higher forming forces. This could be confirmed in this work by strip drawing with bending and deep drawing of cups. The deep drawing forces were about $15 \%$ lower in lubricated deep drawing of cups when drawing clearance was increased from 0.7 to $1 \mathrm{~mm}$. This is comparable to the results of strip drawing with bending. By using a regression analysis of the results of strip drawing with bending, it could be shown that the influence of the drawing radius was significantly higher compared to the influence of the drawing clearance on the forming force. Furthermore, the influence of the drawing radius as well as the influence of the drawing clearance was higher in all experiments in strip drawing with bending when the initial blankholder pressure was increased.

Dry deep drawing of cups could be carried out by using bronze as the reference tool material. There was a high difference of the forming forces in the case of dry metal forming when two different tools with the same geometry were applied. It was assumed that this was caused by production-related tolerances of the drawing dies. However, by using the same tool after removing, cleaning, and mounting again, the forming forces differed in dry metal forming. This may be traced back to assembly-related 
tolerances. However, there was no impact of productionrelated and assembly-related influences in lubricated forming.

In this work, lubricated forming using tool steel led to forming force comparable to those using bronze tool. However, dry forming with steel tool resulted in cup base fracture and wrinkle formation. So, there was no influence of the tool material in lubricated forming but a high influence of the tool material in dry deep drawing of cups. This agrees with the results of strip drawing without bending in a previous work [20]. Bronze showed low friction coefficient against high-alloy steel even at higher blankholder pressure. Dry sliding using tool steel led to high friction coefficient and adhesive wear even at low contact pressure. In contrast, in this work the forming forces were in some cases higher in strip-drawing test with bending when bronze was used as tool material. However, slightly higher forming forces resulted when cold working tool steel was applied as tool material. The factor by which the forces were higher in the case of steel tool amounted to $1.04 \pm 0.05$. This was not influenced by variation of the drawing radius nor of the drawing clearance. It can be concluded that the results of the strip drawing with bending cannot be compared with results of strip drawing without bending or with the results of forming cups.

Avoiding lubrication increased the forming forces by $5-19 \%$ in strip drawing with bending using the reference tool materials. By using the MMC surface in strip drawing with bending, the forming forces were increased from 22 to $23 \%$ by avoiding lubrication even in the case the surface had no depression. It is assumed that this was caused by the different tool properties in the composite material. The Young's modulus of the spherical tungsten carbide [21] is about five times higher compared to the Young's modulus of the aluminum bronze [22]. It is assumed that the matrix of the MMC was slightly impressed when high contact pressure occurred during forming, particularly under the blankholder. In consequence, the particles stood out of the surface and penetrated in the sheet material. This acted as a mechanical hindrance to the movement and higher forming forces were investigated. By the regression analysis, it could be shown that ablation of the matrix by $5 \mu \mathrm{m}$ and using a plateau of hard particles had no significant influence on the forming forces. Furthermore, in deep drawing of cups with higher penetrations of 20$100 \mu \mathrm{m}$ in the die-sinking EDM-machined MMC surface showed the same difference of dry forming to lubricated of around $22 \%$. So, higher penetrations do not significantly influence the forming forces. It was shown that adhesive wear could be reduced by using MMC surface with higher penetration for deep drawing of cups. It is assumed that the high penetration reduced the contact area between the sheet and the bronze matrix. However, using penetration in MMC surface leads to scoring in the cup surface even in lubricated sliding. This agrees with the results of previous work by applying strip drawing without bending. The scoring effect occurred particularly at high contact pressure [20].

\section{Conclusion}

Dry metal forming of high-alloy steel was investigated by strip drawing with bending and deep drawing of cups. The feasibility of dry metal forming by using a MMC tool surface could be demonstrated. Higher forming forces were required compared to a conventional bronze tool. However, adhesive wear of the tool could be reduced by applying MMC tool surface.

It can be concluded that it is appropriate to ablate the matrix of the MMC surface because there is no significant influence on the forming force. The contact area with the matrix can be reduced and thus adhesive wear in dry metal forming can be reduced by a plateau out of hard particles with high penetration.

This work was supported by Deutsche Forschungsgemeinschaft (DFG) within priority program SPP 1676 and the project Se1435/2-2.

\section{References}

1. P. Schmid, M. Liewald, AIP Conf. Proc. 1383 (2011) 446-452

2. B.-A. Behrens, S. Hübner, C. Sunderkötter, J. Knigge, K. Weilandt, K. Voges-Schwieger, Adv. Mater. Res. 22 (2007) $5-15$

3. K. Voges-Schwieger, S. Hübner, B.-A. Behrens, AIP Conf. Proc. 1353 (2011) 224-228

4. N. Bay, E. Ceron, Adv. Mater. Res. 966-967 (2014) $3-20$

5. P. Schmid, Adv. Mater. Res. 769 (2013) 221-228

6. H. Freiße, A. Langebeck, H. Köhler, T. Seefeld, F. Vollertsen, Manuf. Rev. 3 (2016) 1-10

7. N. Bay, A. Azushima, P. Groche, I. Ishibashi, M. Merklein, M. Morishita, T. Nakamura, S. Schmid, M. Yoshid, CIRP Ann. Manuf. Technol. 2 (2010) 760-780

8. A. Almohallami, M. Arghavani, F. Böhmermann, H. Freiße, M. Herrmann, S.A. Mousavi, S. Schöler, P. Scholz, J. Tenner, M. Teller, G. Umlauf, D. Wulff, D. Yilkiran, H.J. Maier, Dry Met. Forming OAJ FMT 3 (2017) 90-94

9. H. Hetzner, J. Koch, S. Tremmel, S. Wartzack, J. Manuf. Sci. Eng. 133 (2011) 1-11

10. S. Kataoka, M. Murakawa, T. Aizawa, H. Ike, Surf. Coat. Technol 177-178 (2004) 582-590

11. A. Pramanik, Trans. Nonferrous Met. Soc. China 26 (2016) 348-358

12. M. Cabeza, G. Castro, P. Merino, G. Pena, M. Roman, Surf. Interface Anal. (2014) 46 861-864

13. A. Grueninger, N. Weidlich, O. Meier, M. Deutschmann, Int. J. Microstruct. Mater. Prop. 5 (2010) 178-192

14. H. Freiße, V. Hohenäcker, T. Seefeld, F. Vollertsen, Dry Met. Forming OAJ FMT 1 (2015) 5-10

15. H. Freiße, J. Vorholt, T. Seefeld, F. Vollertsen, Dry Met. Forming OAJ FMT 3 (2017) 41-44

16. H. Freiße, A. Bohlen, T. Seefeld, J. Mater. Process. Technol. 2018

17. J. Zhang, J. Hu, Image segmentation based on 2D Otsu method with histogram analysis, International Conference on 
Computer Science and Software Engineering, Hubei, China, 22 December 2008, IEEE

18. E. Doege, B.-A. Behrens, Handbuch der Umformtechnik, Grundlagen, Technologien, Maschinen 2 (2010) 324

19. M.T. Farr, Zieh- und Stempelkantenradien beim Tiefziehen, $\mathrm{PhD}$ thesis, University Stuttgart, 67, 2002
20. H. Freiße, S. Schmidt, T. Seefeld, F. Vollertsen, Dry Met. Forming OAJ FMT 4 (2018) 052-058

21. H. Berns, Hartlegierungen und Hartverbund-werkstoffe, Springer, Berlin, 1998

22. H.J. Meigh, Cast and wrought aluminium bronzes: properties, processes and structure, CRC Press, New York, 2000, p. 697

Cite this article as: Hannes Freiße, Adrian Ditsche, Thomas Seefeld, Reducing adhesive wear in dry deep drawing of high-alloy steels by using MMC tool, Manufacturing Rev. 6, 12 (2019) 